\title{
Characteristics of the Double-torsion test to Determine the R-curve of Ceramic Materials
}

\author{
Maria da Consolação Fonseca de Albuquerque ${ }^{\mathrm{a} *}$, José de Anchieta Rodrigues ${ }^{\mathrm{b} *}$ \\ ${ }^{a}$ Civil Engineering Dept., UNESP-Ilha Solteira, Alameda Bahia, 550, Norte, \\ 15385-000 Ilha Solteira - SP, Brazil \\ ${ }^{\mathrm{b}}$ Materials Engineering Dept., UFSCar, Via Washington Luis, Km 235, \\ 13565-905 São Carlos - SP, Brazil
}

Received: September 5, 2005; Revised: October 24, 2006

\begin{abstract}
Double-torsion tests were carried out on a commercial ceramic floor tile to verify whether this test is suitable for determining the R-curve of ceramics. The instantaneous crack length was obtained by means of compliance calibration, and it was found that the experimental compliance underestimates the real crack length. The load vs. displacement curves were also found to drop after maximum loading, causing the stress intensity factor to decline. The R-curves were calculated by two methods: linear elastic fracture mechanics and the energetic method. It was obtained that the average values of crack resistance, $\mathrm{R}$, and the double of the work of fracture, $2 \cdot \gamma_{\text {wof }}$, did not depend on notch length, $\mathrm{a}_{0}$, which is a highly relevant finding, indicating that these parameters were less dependent on the test specimen's geometry. The proposal was to use small notches, which produce long stable crack propagation paths that in turn are particularly important in the case of coarse microstructures.
\end{abstract}

Keywords: double-torsion, $R$-curve, fracture mechanics

\section{Introduction}

The correct selection of a material for mechanical application requires that its intrinsic characteristics should be taken into account, as well as the theoretical conception that introduces the parameters describing its behavior and the relation between those parameters and the material's microstructural characteristics.

When dealing with ceramics, one must keep in mind that they are brittle, fail catastrophically and possess low toughness. The brittle nature of ceramics usually derives from the types of chemical bonds these materials present (an ionic-covalent combination), which also gives the material high tensile strength (because of the high bond strength) and low plastic strain (due to the lack of slip resulting from the high shear modulus and Burgers vector values $)^{1}$.

The mechanical behavior of these materials can be described by the theory of linear elastic fracture mechanics (LEFM), which quantitatively describes the transformation of an intact structural component into a fractured one in response to crack growth. Fracture mechanics refers mainly to the beginning and propagation of one or several cracks subjected to a particular stress field. Crack propagation may be rapid and incontrollable, this means unstable propagation, or slow and stable one.

One way to make a detailed characterization of the crack propagation behavior of a given material is by determining its R-curve. An increasing crack resistance or toughness during crack extension, namely $\mathrm{R}$-curve or $\mathrm{K}^{\mathrm{R}}$-curve behavior, is a direct consequence of energy-dissipating toughening mechanisms which reduce the crack driving force at the crack tip ${ }^{2}$. To obtain this curve experimentally, the stable crack propagation condition is required.

Several geometries can be used to obtain the R-curve ${ }^{3}$, but no standard has so far been defined for this test applied to ceramic materials.

To obtain the R-curve it is necessary crack stable propagation condition. This could be difficult for certain tests, however the double-torsion test eliminates this difficulty.
The concept of the double-torsion configuration was introduced by Outwater and Gerry ${ }^{4,5}$. The development of double-torsion testing techniques and some problems proceeded independently from several different investigations such as Outwater and Austin ${ }^{6}$, Kies and Clark $^{7}$, Beacham et al. ${ }^{8}$, Outwater and Murphy ${ }^{9}$, Evans ${ }^{10,11}$, William and Evans ${ }^{12}$, Mc Kinney and Smith ${ }^{13}$, Outwater et al. ${ }^{14}$, Weidmann and Holloway ${ }^{15}$, Virkar and Johnson ${ }^{16}$, Trantina ${ }^{17}$, Fuller ${ }^{18}$, Pletka and Fuller $^{19}$, Vekinis ${ }^{20}$ et al., Chevalier et al. ${ }^{21}$, Ebrahimi et al. ${ }^{22}$, Ciccotti et al. ${ }^{23}$, Cicotti ${ }^{24}$, Cicotti et al. ${ }^{25}$, Ebrahimi et al. ${ }^{26}$, Pçdzich ${ }^{27}$, Aza et al. ${ }^{28}$, Radovic and Curzio ${ }^{29}$, Zhu et al. ${ }^{30}$, Davies et al. ${ }^{31}$, Nara and Kaneco $^{32}$, Deville et al. ${ }^{33}$, Benaqqa et al. ${ }^{34}$, Pedzich and Wajler ${ }^{35}$. In the last forty years, the double-torsion test has been extensively used to the evaluation of the relation between stress intensity factor, $\mathrm{K}_{\mathrm{I}}$, and crack velocity during sub critical crack growth. However there is not up to now any standard about the conduction of this test to obtain $\mathrm{R}$-curve on ceramic materials.

The double-torsion test is generally mentioned in the literature as a test geometry whose stress intensity factor is in mode $I, K_{I}$, and constant along the propagation of the crack. As the $\mathrm{K}_{\mathrm{I}}$ equation for this test is only a function of the sample's load and dimensions, the crack should propagate with a constant load at a constant displacement rate. Evans ${ }^{10}$ showed that $\mathrm{K}_{\mathrm{I}}$ is constant for the double-torsion test specimen by demonstrating that $\mathrm{K}_{\mathrm{IC}}$ does not depend on the crack's length. The material used by Evans was a glass.

However, Pletka et al. ${ }^{19}$ and Chevalier et al. ${ }^{21}$, among others, did not obtain a constant $\mathrm{K}_{\mathrm{I}}$ during the propagation of the crack along the specimen's entire length. This poses problems in the determination of the R-curve, since the R-curve calculation depends on $\mathrm{K}_{\mathrm{I}}$ values.

Although the double-torsion test easily shows stable crack propagation through a long length of the test specimen, the double-torsion geometry has not often been used to characterize the R-curve of materials. This test is normally cited in the literature for studies of crack propagation velocity as a function of the stress intensity factor

*e-mail: são@dec.feis.unesp.br, josear@power.ufscar.br 
and for the determination of fracture toughness, $\mathrm{K}_{\mathrm{IC}}$. Some of the researchers who have employed the double-torsion test to characterize the R-curve are Vekinis et al..$^{20}$ and Ebrahimi et al. ${ }^{22,26}$.

The purpose of the present study was to apply the double-torsion test to obtain the R-curve through linear elastic fracture mechanics (LEFM) and the energetic method (EM), comparing them to each other. For the determination of R-curve it is necessary to obtain the instantaneous crack length, which in this work has been obtained by experimental compliance calibration of the test specimen. The double-torsion geometry offers the advantages of propagating the crack along the test specimen's longest length. The literature makes no mention of this technique applied to determine the R-curve by the energetic method.

\section{Material}

The material used in tests was a commercial ceramic floor tile whose chemical composition is given in Table 1 .

The ceramic floor tiles (hereinafter referred to as "tiles") were ground to even their surfaces. Longitudinal notches with nominal length of 20, 70, 95, 120 and $180 \mathrm{~mm}$ and $5 \mathrm{~mm}$ width were made at the tiles' mid-span, using a diamond disc. The notch tip had a slop of $45^{\circ}$. This was made to impose a notch similar to the crack profile, which is not straight through the thickness, but extend further along the tensile side of the plate to form a curved crack front. In addition to the notch, the specimens had a $1 \mathrm{~mm}$ deep, $5 \mathrm{~mm}$ wide longitudinal groove on their lower face (surface under tensile stress), starting from the tip of the notch. The purpose of this groove was to keep the crack on an approximately straight propagation path from the notch tip. The nominal dimensions of the test specimens were: thickness $-8 \mathrm{~mm}$, $\mathrm{t}$, width $-107 \mathrm{~mm}$, W, and length $-240 \mathrm{~mm}$, L, with the proportion $\mathrm{t}: \mathrm{W}: \mathrm{L}$ equal to $1: 13: 30$. These proportions are in agreement with the work of Pletka et al. ${ }^{19}$ and Evans et al. ${ }^{11}$.

\section{Experimental Procedure}

All the tests were conducted in an MTS, series 810/458, servohydraulic mechanical testing machine. For double-torsion tests it was used constant displacement rate condition with $1 \mu \mathrm{m} / \mathrm{min}$.

Tests were also conducted to determine Young's modulus, E, using the three-point bending configuration. The calculations were made following the procedure proposed by Hübner and Schuhbauer ${ }^{36}$.

The physical properties of apparent porosity, apparent specific mass of the solid portion and apparent specific mass of the material were obtained by the Archimedes method ${ }^{37}$.

Steel devices were fabricated to fix test specimens for the doubletorsion test. Figure 1 illustrates the basic geometry of the experimental setup, showing the two points where lower loads are applied and the two points of upper loads. These last points are formed by the contact of the upper sphere with the two edges of the notch, thus providing four-point loading.

Figure 2 shows the propagation front of a crack, which propagated up to a certain point under double-torsion. This front, which displays a curvature, is not parallel to the applied load, but extends further along the lower face of the plate (tensile stress) than along the upper

Table 1. Chemical composition of the ceramic floor tile.

\begin{tabular}{cc}
\hline Components & Weight $(\%)$ \\
\hline $\mathrm{SiO}_{2}$ & 65 \\
$\mathrm{Al}_{2} \mathrm{O}_{3}$ & 31 \\
$\mathrm{Fe}_{2} \mathrm{O}_{3}$ & 1 \\
alkalis & 3 \\
\hline
\end{tabular}

face (compressive stress). In Figure 2, the crack is represented by the dark-gray area, which is revealed with red dye. The dark strip along the entire lower portion of the specimen is the groove. The lighter region on the right is the part where the dye did not penetrate, indicating the intact portion of the sample that was fractured manually. The notch is shown at the extreme left of the figure.

The stress intensity factor for the double-torsion test is given by the following Equation ${ }^{12}$ :

$$
\mathrm{K}_{\mathrm{l}}=\mathrm{P} \cdot \mathrm{W}_{\mathrm{m}}\left(\frac{3(1+v)}{\left(\mathrm{W} \cdot \mathrm{t}^{3} \cdot \mathrm{t}_{\mathrm{n}}\right) \varepsilon}\right)^{1 / 2}
$$

where $\mathrm{P}$ is the applied load, $\mathrm{W}_{\mathrm{m}}$ is the lever arm of the torsion moment, $\mathrm{W}$ is the width of the specimen, $\mathrm{t}$ is the thickness of the specimen, $t_{n}$ is the thickness minus the groove length, $v$ is the Poisson's coefficient and $\varepsilon$ is a correction factor for the plate thickness, which is given by ${ }^{16}$ :

$$
\varepsilon=1-0.6302 \cdot\left(\frac{2 \cdot t}{W}\right)+1.20 \cdot\left(\frac{2 \cdot t}{W}\right) \cdot \exp \left(\frac{\pi}{t}\right)
$$

\subsection{Determination of the instantaneous crack length}

To find the instantaneous crack length, $a_{i}$, along its propagation path, the specimen's compliance was calibrated as a function of the initial crack length, $\mathrm{a}_{0}$ (notch length).

In the double-torsion test, the compliance is linearly related with the crack length, according to the following Equation ${ }^{19}$ :

$$
\mathrm{C}_{\mathrm{i}}-\mathrm{C}_{0}=\mathrm{B} \cdot\left(\mathrm{a}_{\mathrm{i}}-\mathrm{a}_{0}\right)=\mathrm{B} \cdot \Delta \mathrm{a}_{\mathrm{i}}
$$

where $C_{i}$ is the compliance for the crack length $a_{i}, B$ is a constant that can be found by compliance calibration ${ }^{18}$ or analytically, $\mathrm{C}_{0}$ is the initial compliance for a sample with notch of the length $\mathrm{a}_{0}$ and $\Delta \mathrm{a}_{\mathrm{i}}=\mathrm{a}_{\mathrm{i}}-\mathrm{a}_{0}$ is the increasing in the crack length.

In this work, B-value was determined experimentally by compliance calibration. So, load-displacement curves (P-d curve) were obtained for specimens with different notch length values as shown in Figure 3a. The slope of the curves in their elastic portion that is given by $\operatorname{tg}(\beta)$ (that is equal $\mathrm{P} / \mathrm{d}$ ) defines the specimen's stiffness. The compliance, $C=1 / \operatorname{tg}(\beta)$, is the reciprocal of stiffness. From line like that one shown in Figure $3 \mathrm{~b}$ is obtained the B-value, which is the slope of the $\mathrm{C}$-a curve, that means $\mathrm{B}=\operatorname{tg}(\phi)$.

The instantaneous crack length can be obtained then by the following equation:

$$
\mathrm{a}_{\mathrm{i}}=\mathrm{a}_{0}+\Delta \mathrm{a}_{\mathrm{i}}=\mathrm{a}_{0}+\frac{\mathrm{C}_{\mathrm{i}}-\mathrm{C}_{0}}{\mathrm{~B}}
$$

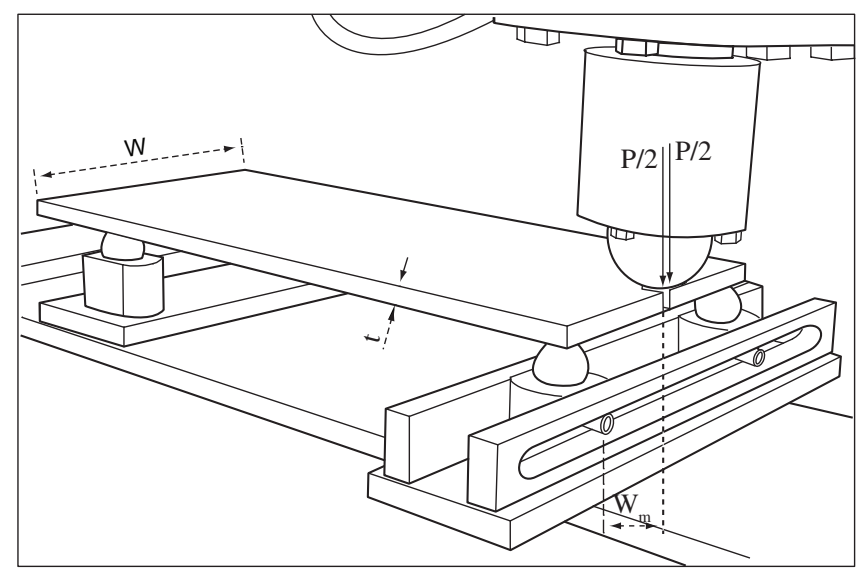

Figure 1. Double-torsion test arrangement showing devices fabricated to carry out the test and some important dimensions. 


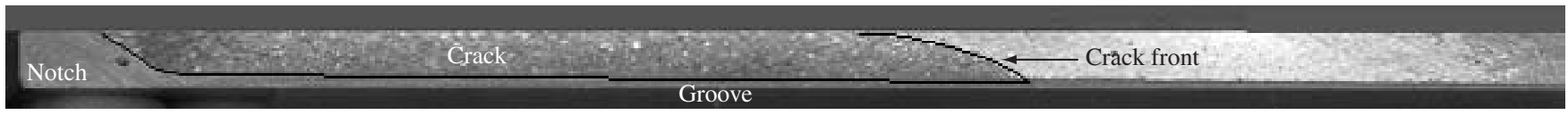

Figure 2. Crack profile of a specimen tested under double-torsion. A black line highlights the crack border.

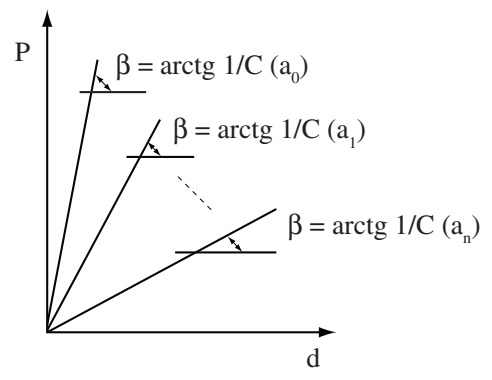

(a)

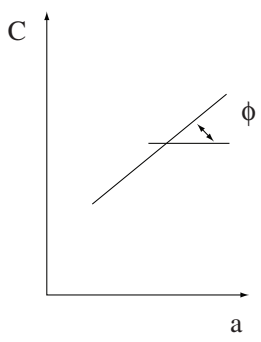

(b)

Figure 3. Obtainment of the compliance - crack length calibration curve for the double-torsion test.

where $\mathrm{C}_{0}$ was calculated for each test from the initial slope of P-d curve in its elastic portion, $\mathrm{C}_{\mathrm{i}}$ was obtained from lines radiating from the origin (Figure 4), where $C_{i}$ is the reciprocal of $\operatorname{tg}\left(\xi_{i}\right)=d_{i} / P_{i}$.

The analytical value for $\mathrm{B}$ is given by the following Equation ${ }^{18}$ :

$$
\mathrm{B}=\frac{3 \cdot \mathrm{W}_{\mathrm{m}}^{2}}{\mathrm{~W} \cdot \mathrm{t}^{3} \cdot \mathrm{G} \cdot \varepsilon}
$$

where $\mathrm{G}$ is the shear modulus.

\subsection{Relation between the average crack propagation velocity, $V$, and $K_{I}$}

Using a simple experimental procedure also enabled us to evaluate the relation between the average crack propagation velocity, $\mathrm{V}$, and the average stress intensity factor, $\mathrm{K}_{\mathrm{I}}$, acting at the tip of the crack during its propagation. The experimental propagation velocity was calculated considering the time it took for the stable crack to propagate. After the natural failure of the specimen, which occurred catastrophically at a critical crack length, $a_{c}$, the total stable propagation path, $\Delta a_{c}$, (it does not include the notch length, a ) was divided by the time interval recorded by the test machine. The value of $a_{c}$ was estimated based on the compliance calibration curve. The theoretical velocity was calculated based on the following equation ${ }^{38}$ :

$$
\mathrm{V}=\frac{\mathrm{d}}{\mathrm{P} \cdot \mathrm{B}}
$$

where $P$ is the average load throughout the stable propagation, $\dot{d}$ is the displacement velocity of the actuator, and B was calculated based on Equation 5.

\subsection{Linear Elastic Fracture Mechanics Method (LEFM)}

The resistance to quasi-static crack propagation, $\mathrm{R}$, was calculated by two methods: LEFM and EM. The LEFM method gives the value of $\mathrm{R}$ by the following equation ${ }^{39}$ :

$$
\mathrm{R}=\frac{\mathrm{K}_{\mathrm{I}}^{2}}{\mathrm{E}}
$$

where the following expression is given by introducing Equation 1:

$$
\mathrm{R}_{\mathrm{i}}=\frac{\mathrm{P}_{\mathrm{i}}^{2} \cdot \mathrm{W}_{\mathrm{m}}^{2} \cdot 3 \cdot(1+v)}{\mathrm{E} \cdot \mathrm{W} \cdot \mathrm{t}^{3} \cdot \mathrm{t}_{\mathrm{n}} \cdot \varepsilon}
$$

where $\mathrm{P}_{\mathrm{i}}$ is the instantaneous load obtained of $\mathrm{P}-\mathrm{d}$ curve, under constant displacement rate and $\mathrm{R}_{\mathrm{i}}$ is the crack propagation resistance at point $\left(\mathrm{P}_{\mathrm{i}}, \mathrm{d}_{\mathrm{i}}\right)$.

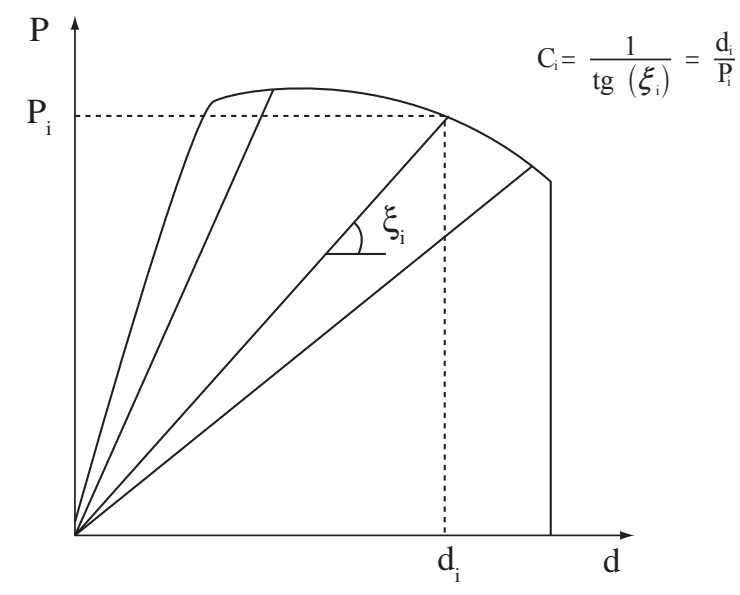

Figure 4. P-d curve for crack stable propagation and lines radiating from the origin for the determination of instantaneous compliance.

\subsection{Energetic Method (EM)}

The energetic method, $\mathrm{EM}^{40}$, determines the consumed energy for small increments in the length of the crack propagation based on the concept that the work made by the test machine to cause the fracture is the area under P-d curve. It is also supposed that all this work is converted in fracture energy under the condition of quasestatic propagation.

For a crack extension, $\Delta \mathrm{a}_{\mathrm{i}}$, from $\mathrm{a}_{\mathrm{i}-1}$ to $\mathrm{a}_{\mathrm{i}}$, the energy necessary for the formation of crack surface, $\mathrm{U}\left(\Delta \mathrm{a}_{\mathrm{i}}\right)$, is given by the area between the lines drawn from the origin to the points $\left(\mathrm{P}_{\mathrm{i}-1}, \mathrm{a}_{\mathrm{i}-1}\right)$ and $\left(\mathrm{P}_{\mathrm{i}}, \mathrm{a}_{\mathrm{i}}\right)$. In Figure $5 \mathrm{a}_{\mathrm{i}}$ represents a crack length corresponding to position $\mathrm{d}_{\mathrm{i}}$ of the actuator. In the same way, $\Delta \mathrm{a}_{\mathrm{i}}$ corresponds to $\Delta \mathrm{d}_{\mathrm{i}}$.

Using the EM method, $\mathrm{R}$ was calculated based on the following equation $^{40}$ :

$$
\mathrm{R}_{\mathrm{i}}=\frac{\mathrm{U}\left(\Delta \mathrm{a}_{\mathrm{i}}\right)}{\mathrm{t}_{\mathrm{n}} \cdot \Delta \mathrm{a}_{\mathrm{i}}}
$$

The denominator $\mathrm{t}_{\mathrm{n}} \cdot \Delta \mathrm{a}_{\mathrm{i}}$ represents the corresponding increment in the area of propagation.

\subsection{The criterion to check the $R$-values}

The criterion to check if the $\mathrm{R}$-values are reliable is to compare the average $R$ value, $\bar{R}$, with the double of the work of fracture, $2 \cdot \gamma_{\text {wof }}$, according to the following equation ${ }^{40-42}$ :

$$
\overline{\mathrm{R}}=2 \cdot \gamma_{\text {wof }}
$$

To apply this criterion, the value of $\overline{\mathrm{R}}$ was calculated for the energetic method, $\overline{\mathrm{R}}(\mathrm{EM})$, and the LEFM method, $\overline{\mathrm{R}}(\mathrm{LEFM})$, using the following relation:

$$
\overline{\mathrm{R}}=\left(\frac{1}{\mathrm{a}_{\mathrm{c}}-\mathrm{a}_{0}}\right) \cdot \int_{\mathrm{a}_{0}}^{\mathrm{a}_{\mathrm{c}}} \mathrm{R}(\mathrm{a}) \mathrm{da}
$$

where $a_{c}$ is the last crack length still under stable propagation. The integral that appear in Equation 11 was calculated numerically by the trapezoid method. 
To determine the work of fracture $\gamma_{\text {wof }}$, the work performed by the test machine on the sample had to be calculated, according to Nakayama ${ }^{43}$, in relation to the entire stable crack propagation path. The area under the P-d curve up to the catastrophic propagation point was divided by the corresponding projected fracture surface area. The elastic energy stored in the system at the catastrophic propagation point was also subtracted from the work performed by the test machine. Figure 6 illustrates the integrated area of the P-d curve.

Based on Figure 6, the value of $\gamma_{\text {wof }}$ is given by the following equation:

$$
\gamma_{w o f}=\frac{U_{c}}{2 \cdot \mathrm{t}_{\mathrm{n}} \cdot \Delta \mathrm{a}_{\mathrm{c}}}=\frac{\int_{0}^{\mathrm{d}_{\mathrm{c}}} \mathrm{P} \cdot \mathrm{dd}-\frac{1}{2} \mathrm{P}_{\mathrm{c}} \cdot \mathrm{d}_{\mathrm{c}}}{2 \cdot \mathrm{t}_{\mathrm{n}} \cdot \Delta \mathrm{a}_{\mathrm{c}}}
$$

where $\mathrm{P}_{c}$ and $\mathrm{d}_{c}$ are, respectively, the actuator's force and displacement at the point where catastrophic propagation began, and $\Delta a_{c}=a_{c}-a_{0}$, with $a_{c}$ obtained from the compliance calibration curve.

\section{Results and Discussion}

The average value of Young's modulus of the material used in this work was $58 \mathrm{GPa} \pm 4 \mathrm{GPa}$. The values of apparent porosity, ap-

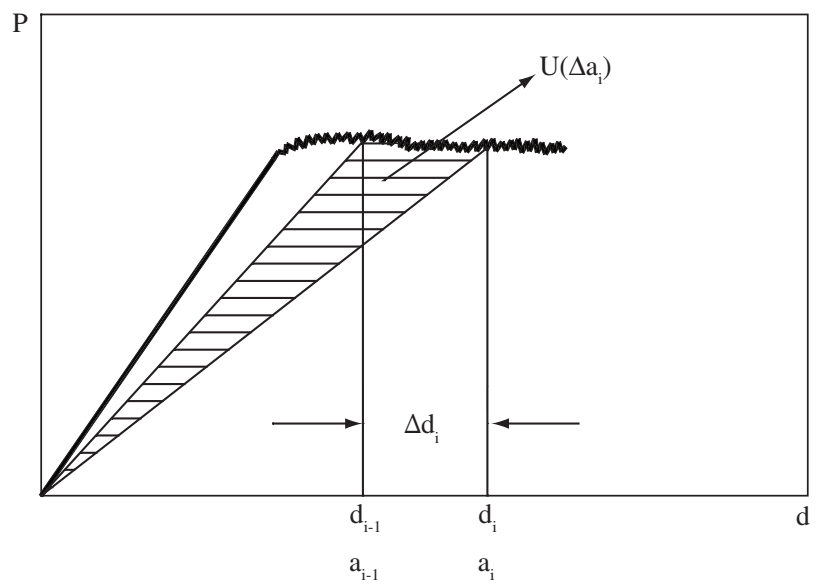

Figure 5. Energetic Method: energy, $\mathrm{U}\left(\Delta \mathrm{a}_{\mathrm{i}}\right)$, corresponding to an increase in the machine displacement, $\Delta \mathrm{d}_{\mathrm{i}}$.

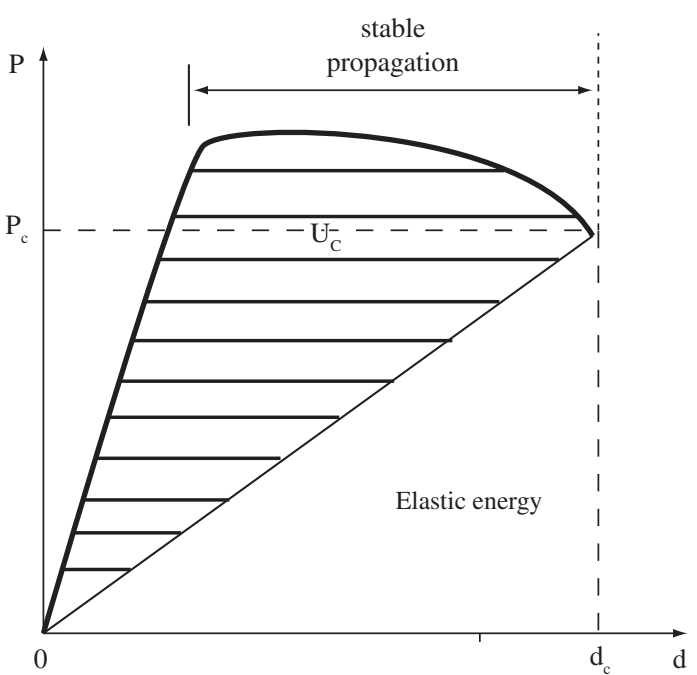

Figure 6. Graphic representation of the calculation of work of fracture, $\gamma_{\text {wof }}$, based on the measurement of the area under the P-d curve. parent specific mass, and apparent specific mass of the solid portion, were $12.1 \pm 0.5 \%$ - vol, $3.15 \pm 0.05 \mathrm{~g} / \mathrm{cm}^{3}$ and $3.56 \pm 0.06 \mathrm{~g} / \mathrm{cm}^{3}$, respectively.

Figure 7 depicts the compliance calibration curve. Its equation, obtained from the linear regression of the points in Figure 7, with units of " $\mathrm{m} / \mathrm{N}$ " for $\mathrm{C}$ and " $\mathrm{m}$ " for a, are shown below:

$$
\mathrm{C}=4.16 \times 10^{-6} \cdot \mathrm{a}+3.05 \times 10^{-7}
$$

The compliance calibration curve found through the experimental method (Figure 7) provided a slope (B-value) of $4.16 \times 10^{-6} \mathrm{~N}^{-1}$. The theoretical average value of $\mathrm{B}$ (Equation 5) calculated for all samples was $5.5 \times 10^{-6} \mathrm{~N}^{-1}$.

The literature normally shows the P-d graph for the double-torsion test with the elastic region (load increase), the crack propagation portion (approximately constant load) and the rupture (sudden load drop) under constant displacement rate condition. In the double-torsion test, the crack propagates catastrophically starting from a given length, defined here as the critical crack length, $a_{c}$.

Figure 8 shows the critical crack length, ac, vs. notch length, clearly showing that the notch length did not influence the critical crack length. The straight horizontal line in this figure indicates an average value of $17.7 \mathrm{~cm}$ for $\mathrm{a}_{\mathrm{c}}$, which represents $71 \%$ of the total length of the specimen. Thus, the smaller the notch length, the longer the stable propagation of the crack, $\Delta \mathrm{a}$. This is a favorable aspect of the double-torsion test in terms of the interest in determining the R-curve, since it requires long stable crack propagation lengths, which can be achieved with small notches. In this context, we highlight

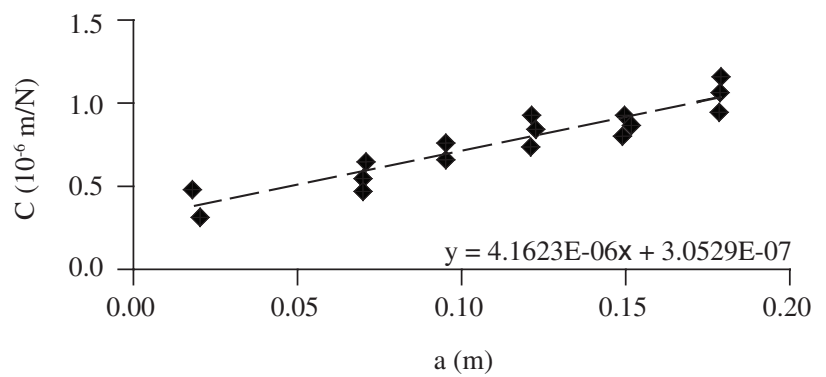

Figure 7. Calibration curve for compliance, C, vs. crack length, a. In this case, a represents the notch length.

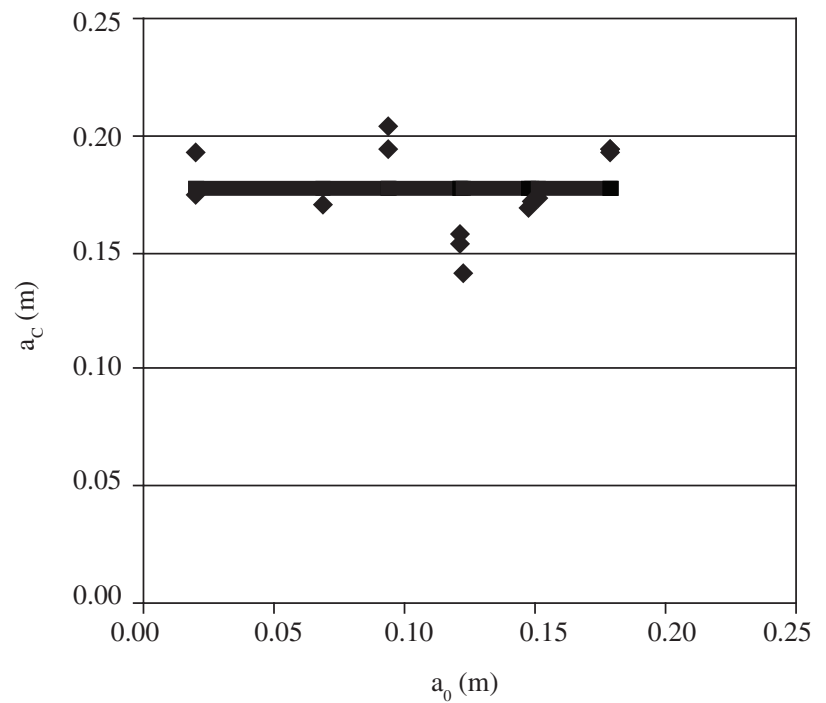

Figure 8. Critical crack length, $\mathrm{a}_{\mathfrak{c}}$, vs. notch length, $\mathrm{a}_{0}$. 
another interesting aspect of the double-torsion test in comparison with three- or four-point bending tests: for the latter tests, the shorter the notch, the higher the tendency for unstable crack propagation, thus hindering control of the propagation. The opposite holds true in double-torsion: long stable crack propagations are obtained even with small notches (Figure 8).

Although the double-torsion test is, in theory, a test with a constant $\mathrm{K}_{\mathrm{I}}$ value, two different types of P-d curve were observed in this work, as indicated in Figure 9. In type 1, there was almost no stable crack propagation, i.e., the specimen failed shortly after maximum load point. This occurred with all the specimens whose notch length exceeded $\mathrm{a}_{c}$.

The type 2 curve showed a progressively decreasing load as the crack length increased along its stable propagation. Pletka et al. ${ }^{19}$ also observed a decrease in $\mathrm{P}$, indicating that $\mathrm{K}_{\mathrm{I}}$ is not effectively constant in the double-torsion test. Based on the $\mathrm{V} \times \mathrm{K}_{\mathrm{I}}$ graph, those authors confirmed that $\mathrm{K}_{\mathrm{I}}$ decreased in subsequent relaxation tests after sections of crack propagation in the same specimen using the double-torsion geometry. This behavior, however, was not observed with glass.

Figure 10 shows the average crack propagation velocity, $\overline{\mathrm{V}}$, as a function of notch length. The $\mathrm{K}_{\mathrm{I}}$ value used here was the arithmetic average of all the instantaneous $\mathrm{K}_{\mathrm{I}}$-values after initiation of the crack propagation in each test. This figure indicates that the experimental crack propagation velocity showed a significant dispersion when compared with the theoretical value (Equation 6). Figure 10 clearly shows that, for small notch sizes, the congruence between experimen-

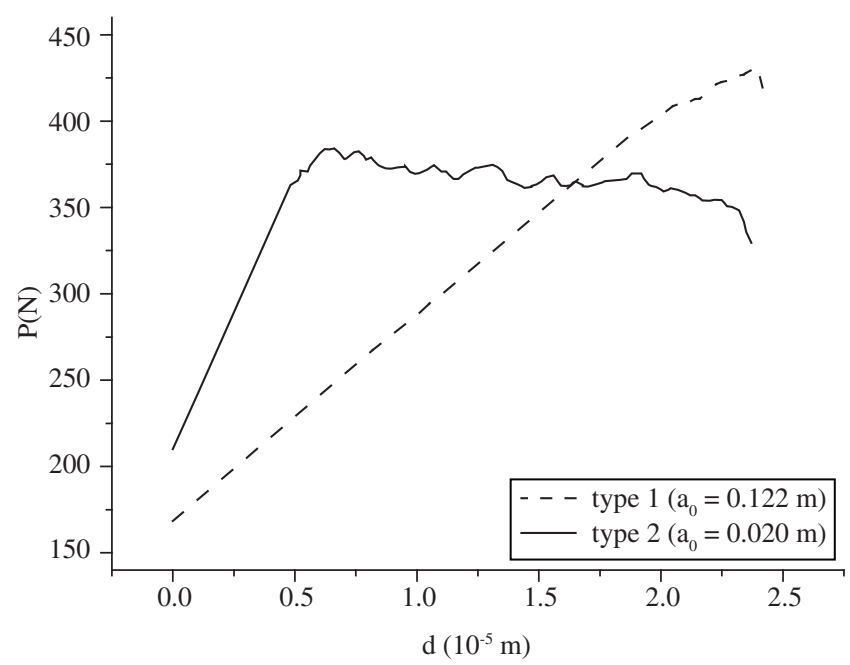

Figure 9. Two different types of P-d curve.

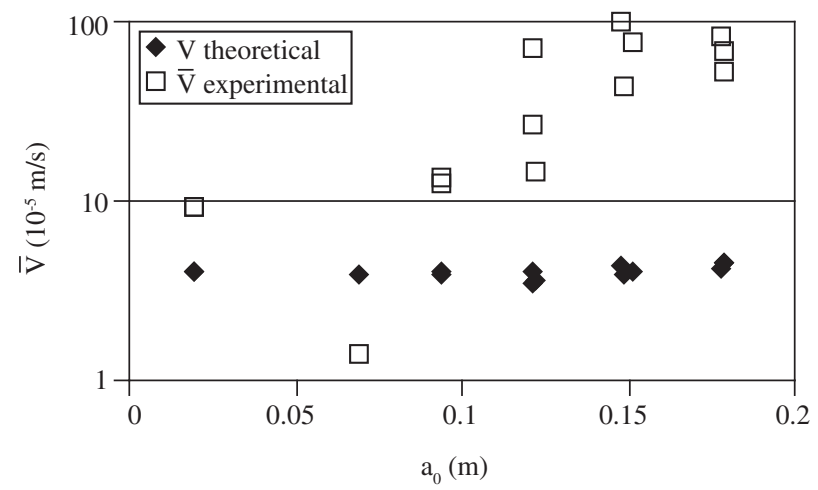

Figure 10. Average velocity of crack propagation, $\overline{\mathrm{V}}, v s . \mathrm{a}_{0}$. tal and theoretical propagation velocities was quite good due to the more precise determination of the length of stable crack propagation $\left(\Delta \mathrm{a}_{\mathrm{C}}=\mathrm{a}_{\mathrm{C}}-\mathrm{a}_{0}\right)$ in this condition.

Based on the greater length of crack propagation with shorter notch lengths, the lesser scattering in crack propagation velocities with shorter notch lengths, and the greater similarity between experimental and theoretical propagation velocities using shorter notch lengths which were found in this study, we recommend the use of smaller notch lengths in the double-torsion test. This represents a significant advantage for interest in R-curve studies, for one has a sample with a longer stable propagation path than that achieved with other, more commonly used geometries. This point is particularly important when ceramics with coarse microstructures are involved, as in the case of refractories.

Figure 11 gives three examples of R-curves for notch lengths of $0.02 \mathrm{~m}, 0.07 \mathrm{~m}$ and $0.095 \mathrm{~m}$ obtained by the LEFM and EM methods. The a-values of the R-curves were calculated according to Equation 4 and the description in section 3.1. For the longest notch lengths, the number of points of the P-d curve after the maximum load was very few due to the short extension of $\Delta \mathrm{a}_{\mathrm{c}}$, so the R-curves for these samples were not considered representative and are not shown here.

The first point to note about the R-curves in Figure 11 is that they show no variation in shape when calculated by the LEFM and EM methods.

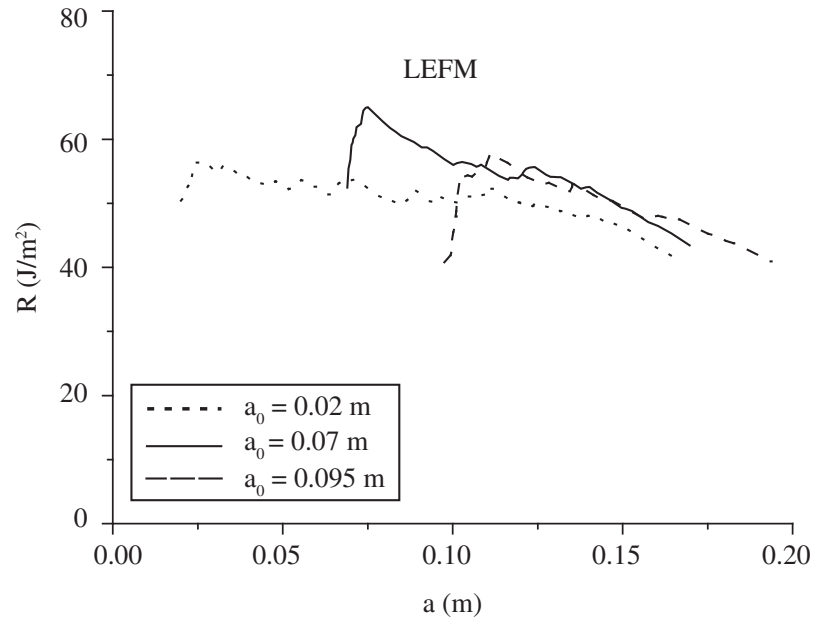

(a)

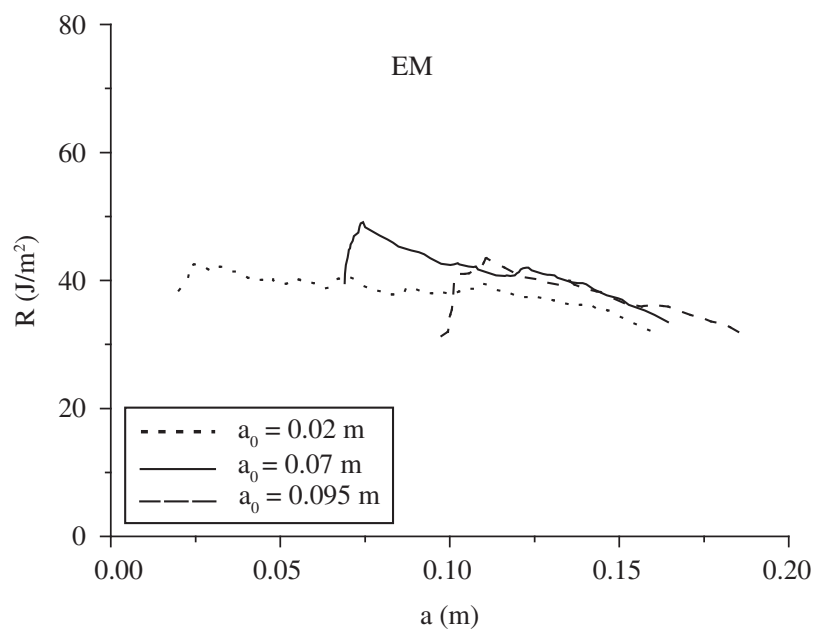

(b)

Figure 11. Examples of R-curves of test specimens with $\mathrm{a}_{0}=0.02 \mathrm{~m}, 0.07 \mathrm{~m}$ and $0.095 \mathrm{~m}$, calculated by the LEFM a) and EM b) methods. 
The maximum $\mathrm{R}$-value is given for the same crack length by both methods, but the R-values obtained with EM are smaller.

The R-curves found by the two methods showed declining values after reaching the highest peak (Figure 11). This decrease was associated with the shape of the P-d curves, which displayed the same characteristics. As mentioned earlier, when they applied the doubletorsion geometry to other materials, Pletka et al. ${ }^{19}$ also observed a decrease in load and, hence, a drop in $\mathrm{K}_{\mathrm{I}}$ as the crack propagated. Using a bending test, Saadaoui et al. ${ }^{44}$ also observed a drop in the $\mathrm{R}$-curve for partially stabilized zirconia. The authors showed that the drop in that material occurred due to the low velocity at which the load was applied, which caused the crack propagation to occur predominantly by corrosion. This was confirmed when the velocity at which the load was applied was increased and the drop no longer occurred. In the present work, tests were conducted to check if this phenomenon occurred with the material under study here. Our results indicated that this was apparently not the case, since our material continued to show a declining load up to 20-fold higher at the actuator's displacement velocity, as depicted in Figure 12.

According to $\mathrm{Sakai}^{45}$, a material composed of large-size grains shows an increasing rather than a decreasing R-curve. Moreover, various ceramics with coarse microstructures show that the behavior of the R-curve is related to the bridging mechanism in the crack wake, involving interlocking and friction between grains ${ }^{26}$. Therefore, this material should show an upward R-curve.

Chevalier et al. ${ }^{21}$ propose an empirical correction factor as a function of the crack's relative length, $\mathrm{a} / \mathrm{a}_{0}$, elevated to an exponent, $\mathrm{x}$, which depends on the specimen's material and dimensions. Thus, $\mathrm{K}_{\mathrm{I}}$ is now dependent on the crack length. According to Chevalier et al. ${ }^{21}$, double-torsion tests with constant loading and relaxation tests would be required to determine the value of $\mathrm{x}$. However, these tests were not our objective. The aim was to study the double-torsion test to obtain the R-curve by the two methods EM and LEFM and make comparison one each another. Beside this, it was not possible to do the correction for the energetic method because the error has its origin in the experimental P-d curve and the correction in LEFM

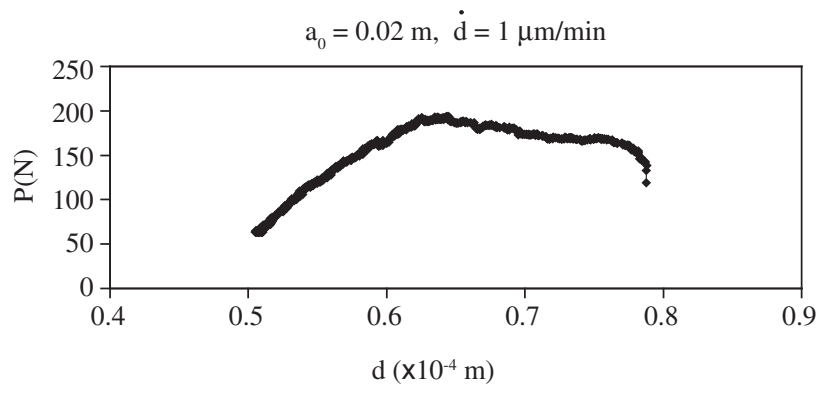

(a)

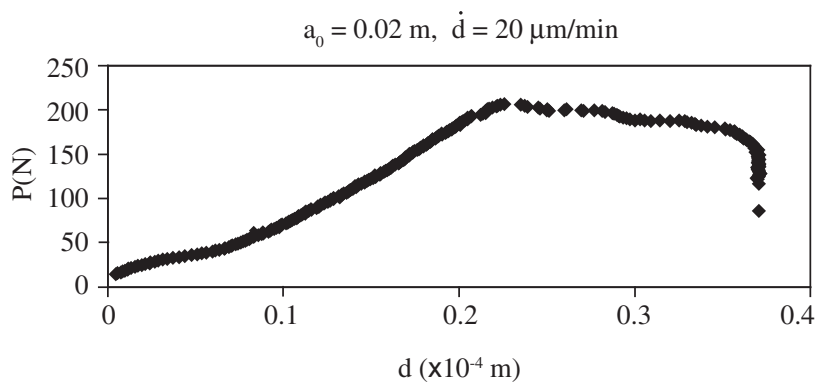

(b)

Figure 12. $\mathrm{P}$-d curves for a) $\dot{d}=1 \mu \mathrm{m} / \mathrm{min}$ and $\mathrm{b}$ ) $\dot{d}=20 \mu \mathrm{m} / \mathrm{min}$. method introduced by Chevalier et al. ${ }^{21}$, has been made on the stress intensity factor equation and not on the P-d curve. In this way would be impossible compare the value of R(EM) and R(LEFM).

$\mathrm{Ciccotti}^{24}$, has also proposed corrections for $\mathrm{K}_{\mathrm{I}}$, however it was not possible to use them in this work because they are corrections for $\mathrm{K}_{\mathrm{I}}$ and not for P-d curve. Beside this, the corrections proposed by Ciccotti are valid only for specimens with length of $17 \mathrm{~cm}(6$ and $10 \mathrm{~cm}$ of width) and of $25 \mathrm{~cm}$ ( 6 and $10 \mathrm{~cm}$ of width). These were not the case of the specimens of the present work.

It was found that, after reaching its peak, the P-d curve showed an increasing downward tendency as $\mathrm{a}_{0}$ increased (Figure 11). This was probably because the length of stable propagation, $\Delta \mathrm{a}_{\mathrm{C}}$, decreased and the catastrophic fracture effect became more evident in the P-d curve, which would force a more intense correction factor, according to procedure of Chevalier et al. ${ }^{21}$. Therefore, the most reliable $\mathrm{R}$-values should be the ones calculated with low $\mathrm{a}_{0}$-values and high $\Delta \mathrm{a}_{\mathrm{C}}$-values.

Table 2 displays the values of $\overline{\mathrm{R}}(\mathrm{EM}), \overline{\mathrm{R}}(\mathrm{LEFM})$ and $2 \cdot \gamma_{\text {wof }}$. From this table, it can be seen that, generally speaking, $\bar{R}(\mathrm{EM})$ presents a value more congruent with $2 \cdot \gamma_{\text {wof }}$ than $\bar{R}(\mathrm{LEFM})$. The value of $\overline{\mathrm{R}}(\mathrm{LEFM})$ was $19 \%$ higher than $2 \cdot \gamma_{\text {wof }}$, while $\overline{\mathrm{R}}(\mathrm{EM})$ was $9 \%$ lower. It can also be observed that $\bar{R}(\mathrm{EM}), \overline{\mathrm{R}}(\mathrm{LEFM})$ and $2 \cdot \gamma_{\text {wof }}$ did not change with $\mathrm{a}_{0}$.

The average $\mathrm{R}$-value was also calculated considering only increasing values of $\mathrm{R}$ up to the highest point, $\overline{\mathrm{R}}_{\mathrm{HP}}$. The value of $\bar{R}_{H P}$ (LEFM) was $57 \pm 7 \mathrm{~J} / \mathrm{m}^{2}$ and $\bar{R}_{H P}$ (EM) was $44 \pm 5 \mathrm{~J} / \mathrm{m}^{2}$. Therefore, the values of $\overline{\mathrm{R}}_{\mathrm{HP}}$ were $7 \%$ higher than $\mathrm{R}_{0}$ for LEFM and $9 \%$ higher for EM, revealing the occurrence of wake buildup mechanisms, i.e., an increasing R-curve.

The values of initial crack resistance, $\mathrm{R}_{0}$, were also obtained and were $53 \pm 8 \mathrm{~J} / \mathrm{m}^{2}$ and $40 \pm 6 \mathrm{~J} / \mathrm{m}^{2}$, respectively, by the LEFM and EM methods. The $\mathrm{R}_{0}$ value corresponds to the first point where the crack begins to propagate.

Figure 13 indicates that $\mathrm{R}_{0}$ also did not change with $\mathrm{a}_{0}$, except with a notch length of $0.18 \mathrm{~m}$, when the $\mathrm{R}_{0}$ value was lower. However, no stable propagation occurred with this notch length, which was already greater than the critical length, $a_{c}$, and should therefore not be considered.

\section{Conclusions}

- Double-torsion is a suitable method to determine the R-curve, for the crack propagates along the longest dimension of the sample;

- The double-torsion method presents a crack length where catastrophic propagation occurs, herein called critical crack length, $\mathrm{a}_{\mathrm{c}}$, under constant displacement rate condition. This length did not vary with notch length and occurred, on average, over $71 \%$ of the specimen's length. Because the critical crack length did not vary with notch length, the samples with smaller notches showed longer stable crack propagation paths, $\Delta \mathrm{a}_{\mathrm{c}}$;

- The analytical and experimental values of B were in agreement;

Table 2. $\overline{\mathrm{R}}(\mathrm{EM}), \overline{\mathrm{R}}(\mathrm{LEFM})$ and $2 \cdot \gamma_{\text {wof }}$ values for the commercial ceramic floor tile.

\begin{tabular}{cccc}
\hline $\mathrm{a}_{0}(\mathrm{~m})$ & $\overline{\mathrm{R}}(\mathrm{EM})\left(\mathrm{J} / \mathrm{m}^{2}\right)$ & $\overline{\mathrm{R}}(\mathrm{LEFM})\left(\mathrm{J} / \mathrm{m}^{2}\right)$ & $2 \cdot \gamma_{\text {wof }}\left(\mathrm{J} / \mathrm{m}^{2}\right)$ \\
\hline 0.02 & $38+1$ & $50+2$ & $40+2$ \\
0.07 & $41+3$ & $54+5$ & $48+4$ \\
0.095 & $39+3$ & $51+4$ & $43+4$ \\
Overall average & $39+3$ & $51+4$ & $43+4$ \\
\hline
\end{tabular}




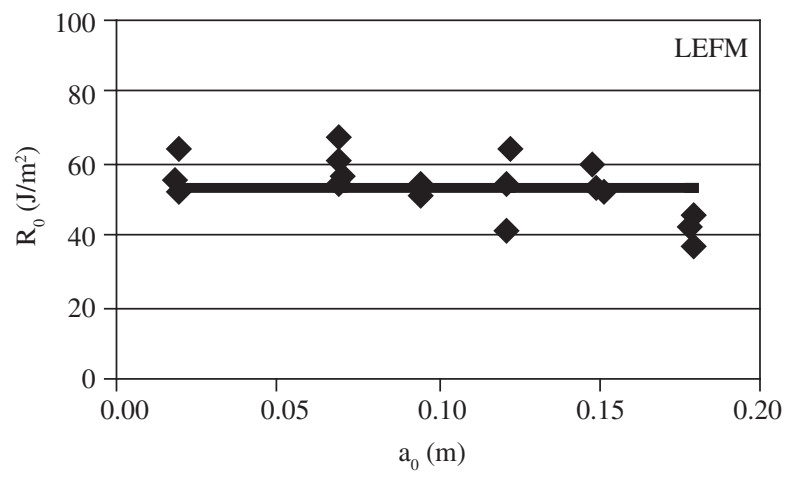

(a)

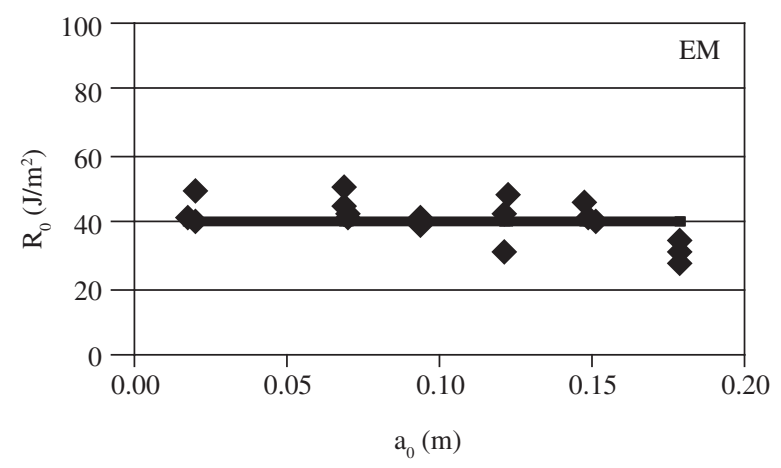

(b)

Figure 13. Initial crack propagation resistance, $\mathrm{R}_{0}$, vs. $\mathrm{a}_{0}$ : a) LEFM and b) EM.

- The longer length of stable propagation with shorter notch lengths, the lesser scattering in crack propagation velocities with shorter notch lengths, and the greater similarity between experimental and theoretical propagation velocities using shorter notch lengths suggest the validity of using shallower notches in the double-torsion test. This is a significant advantage in R-curve studies, for one has a specimen with a longer stable propagation path than that achieved with other, more commonly used geometries. This point is particularly important in the case of ceramics with coarse microstructures;

- P vs. d curves showed a decline, which was reflected in the R-curve. For the material used here, the low testing velocity did not cause this drop, which, albeit increased 20-fold, was unable to prevent this decline;

- The R-curves showed the same shape when obtained through the LEFM and EM methods, however, although the LEFM method led to higher values;

- The criterion adopted to evaluate the reliability of the R-values was the comparison of the average values of $\mathrm{R}, \overline{\mathrm{R}}$, and $2 \cdot \gamma_{\text {wof }}$. The result indicated the relation $\overline{\mathrm{R}}(\mathrm{EM})<2 \cdot \gamma_{\text {wof }}<\overline{\mathrm{R}}(\mathrm{LEFM})$. The ceramic material used here presented an $\bar{R}(\mathrm{EM})$ more similar to $2 \cdot \gamma_{\text {wof }}$; and

- The double-torsion method proved suitable for determining the R-curve of ceramic materials, easily reaching stable crack propagation. Therefore, this method deserves further studies aimed at reaching the $\mathrm{R}$-curves of materials with coarse microstructures, as is the case of refractory castables, particularly in order to understand the drop in the $\mathrm{P} v s$. d curve and, hence, the R-curve after it reaches its highest point.

\section{Acknowledgments}

The authors would like to thank Cerâmica Saffran S. A., FAPESP (Brazil) CNPq (Brazil) and PROPe/UNESP (Brazil) for their support and Dr. Walter Libardi, UFSCar/DEMa for his pertinent discussions.

\section{References}

1. Hayden W, Moffatt WG, Wulff J. Structure and properties of materials: mechanical behavior; v. 3, New York John: Wiley \& Sons; 1965. p. 247.

2. Lutz EH, Claussen N, Swain M V. KR-Curve behavior of duplex ceramics Journal of American Ceramic Society. 1991; 74(1):11-18.

3. Sakai M. Fracture Toughness Testing, Fracture Mechanisms and R Curve Behavior of Brittle Materials. Lecture in Departamento de Engenharia de Materiais. UFSCar; 1992 March.

4. Outwater JO, Gerry DJ. On the fracture energy of glass NRL Interim Contract Report, Contract NONR 3219 (01) (x), AD 640848, University of Vermont, Burlington, Vt., 1966 Aug.

5. Outwater JO, Gerry DJ. On the fracture energy, rehearing velocity and refracture energy of cast epoxy resin. Journal of Adhesion. 1969; 1:290-298.

6. Outwater JO, Austin LE. Effect of external hydrostatic pressure on damage glass hydrospheres. In: ASTM International, editor. Materials Performance and the Deep Sea. Philadelphia: American Society for Testing and Materials; 1969. p. 41-54.

7. Kies JA, Clark ABJ. Fracture propagation rates and times to fail proof stresses in bulk glass. In: P. L. Pratt, editor. Proceedings of the Second International Conference on Fracture; 1969 Apr 13-18; Brighton, England. London: Chapman and Hall Ltd.; 1969. p. 483-491.

8. Beachem CD, Kies JA, Brown BF. Constant K specimen for stress corrosion cracking tests. Materials Research and Standards. 1970; 11(4):30.

9. Outwater JO, Murphy MC. On the fatigue of epoxy resin. In: Proceedings of the Twenty Six Annual Technology Conference Reinforce Plastic; 1971; Washington, DC. Washington: Compos Division Proceedings; 1971. p. 6.

10. Evans AG. A method for evaluating the time-dependent failure characteristics of brittle materials - and its application to polycrystalline alumina. Journal of Materials Science. 1972; 7(10):1137-1146.

11. Evans AG, Linzer M, Russell LR. Acoustic emission and crack propagation in polycrystalline alumina. Materials Science and Engineering. 1974; 15(2-3):253-261.

12. Williams DP, Evans AG. A simple method for studying slow crack growth. Journal of Testing and Evaluation. JTEVA. 1973; 1(4):264-270.

13. McKinney KR, Smith HL. Method of studying subcritical cracking of opaque materials. Journal of the American Ceramic Society. 1973; 56(1):30-32.

14. Outwater JO, Murphy MC, Kumble RG, Berry JT. Double Torsion Technique as a universal fracture toughness test method. In: ASTM editor. Fracture toughness and slow-stable cracking. Philadelphia: American Society for Testing and Materials; STP 559. 1974. p. 127-138.

15. Weidmann GW, Holloway DG. Slow crack propagation in glass Physics and Chemistry of Glasses. 1974; 15(5):116-122.

16. Virkar AV, Johnson DL. Fracture behaviour of $\mathrm{ZrO} / / 2-\mathrm{Zr}$ Composites Journal of the American Ceramic Society. 1976; 59(5-6):197-200.

17. Trantina GG. Stress Analysis of the double-torsion specimen. Journal of the American Ceramic Society. 1977; 60(7-8):338-341.

18. Fuller ER Jr. An Evaluation of Double Torsion Testing - Analysis, Fracture Mechanics Applied to Brittle Materials. ASTM STP 678. S. W. Freiman, Ed., American Society for Testing and Materials. 1979; p. 3-18.

19. Pletka BJ, Fuller ER Jr, Koepke BG. An Evaluation of Double Torsion Testing - Experimental, Fracture Mechanics Applied to Brittle Materials. ASTM STP 678. S. W. Freiman, Ed., American Society for Testing and Materials. 1979; p. 19-37. 
20. Vekinis G, Ashby MF, Beaumont PWR. R-Curve behaviour of $\mathrm{Al}_{2} \mathrm{O}_{3}$ ceramics. Acta metallurgica et Materialia. 1990; 38(6):1151-1162.

21. Chevalier J, Saadaoui M, Olagnon C, Fantozzi G. Double-Torsion Testing a 3Y-TZP Ceramic. Ceramics International. 1996; 22(2):171-177.

22. Ebrahimi ME, Chevalier J, Fantozzi G. Slow crack-growth behavior of alumina ceramics. Journal of Materials Research. 2000; 15(1):142-147.

23. Ciccotti M, Gonzato G, Mulargia F. The double torsion loading configuration for fracture propagation: an improved methodology for the load relaxation at constant displacement. International Journal of Rock Mechanics \& Mining Sciences. 2000; 37:1103-1113.

24. Ciccotti M. Realistic finite-element model for the double torsion loading configuration. Journal Americam Ceramic Society. 2000; 83(11):2737-2744.

25. Ciccotti M, Negri N, Gonzato G, Mulargia F. Practical Application of an Improved Methodology for the Double-Torsion Load Relaxation Method. International Journal of Rock Mechanics \& Mining Sciences. 2001; 38:569-576.

26. Ebrahimi ME, Chevalier J, Fantozzi G. R-Curve Evaluation and Bridging Stress Determination in Alumina by Compliance Analysis. Journal of the European Ceramic Society. 2003; 23(6):943-949.

27. Pçdzich Z. The reability of particulate composites in the TZP/WC system. Journal of the European Ceramic Society. 2004; 24(12):3427-3430.

28. Aza AH, Chevalier J, Fantozzi G. Slow-crack-growth behaviour of zirconia-toughened alumina ceramics processed by different methods. Journal of the American Ceramic Society. 2003; 86(1):115-120.

29. Radovic M, Lara-Curzio E. Mechanical properties of tape cast nickelbased anode materials for solid oxide fuel cells before and after reduction in hydrogen. Acta Materialia. 2004; 52(20):5747-5756.

30. Zhu P, Lin Z, Chen G, Kiyohiko I. The predictions and applications of fatigue lifetime in alumina and zirconia ceramics. International Journal of Fatigue. 2004; 26(10):1109-1114.

31. Davies AR, Field JE, Takahashi K, Hada K. Tensile and fatigue strength of free-standing CVD diamond. Diamond and Related Materials. 2005; 14(1):6-10.

32. Nara Y, Kaneco K. Study of sub critical crack growth in andesite using the double-torsion test. International Journal of Rock Mechanics and Mining Sciences. 2005; 42(4):521-530.
33. Deville S, Asan El A, Chevalier J. Atomic force microscopy of transformation toughening in ceria-stabilized zirconia. Journal of the European Ceramic Society. 2005; 25(13):3089-3096.

34. Benaqqa C, Chevalier J, Saadaoui M, Fantozzi G. Slow crack growth behaviour of hydroxyapatite ceramics. Biomaterials. 2005; 26(31):61066112 .

35. Pçdzich Z, Wajler C. Slow crack propagation in Y-TZP/metal composites. Journal of the European Ceramic Society. 2006; 26(4-5):679-682.

36. Hübner H, Schuhbauer H. Experimental Determination of fracture Mechanics Stress Intensity Calibration in Four-point Bending. Engineering Fracture Mechanics. 1977; 9(2):403-410.

37. Wilson MA, Carter MA, Hoff WD. British standard and RILEM water absorption tests: a critical evaluation. Materials and Structures. 1999; 32(222):571-578.

38. Evans AG, Wiederhorn SM. Crack propagation and failure prediction in silicon nitride at elevated temperatures. Journal of Materials Science. 1974; 9(2):270-278

39. Whittaker BN, Sing RN, Sun G. Rock Fracture Mechanics - Principles, Design and Applications. Amsterdam: Elsevier Science; 1992. p. 90.

40. Bornhauser A, Kromp K, Pabst RF. R-Curve evaluation with ceramic materials at elevated temperature by an energy approach using direct observation and compliance calculation of the crack length. Journal of Materials Science. 1985; 20(7):2586-2596.

41. Rodrigues JA, Pandolfelli VC. Comportamento de curva-R de refratários de MgO-C Cerâmica. 2000; 46(297):40-47.

42. Salvini VR, Pandolfelli VC, Rodrigues JA. Avaliação dos parâmetros teóricos R“' e Rst como indicativos de desempenho termomecânico de materiais refratários. In: Anais do $12^{\circ}$ Congresso Brasileiro de Ciências e Engenharia de Materiais CBECIMAT, 1995; Aguas de Lindoia, SP, v. 1, p. $472-477$.

43. Nakayama J. Direct Measurement of fracture energies of brittle heterogeneous materials. Journal of American Ceramic Society. 1965; 48(11):583587

44. Saadaoui M, Olagnon C, Fantozzi G. Influence of Precracking Procedure, Environment, Temperature and Microstructure on R-Curve Behaviour of Alumina and PSZ Ceramics. Journal of European Ceramic Society. 1993; 12(5):361-368.

45. Sakai M. Fracture Mechanics of Refractory Materials. Taikabutsu Overseas. $1987 ; 8(2): 4-12$ 